\title{
Configuración de identidades en contextos migratorios: indagación de prácticas cotidianas en peluquerías dominicanas en Santiago de Chile
}

\section{Configuration of identities in migratory contexts: investigation of daily practices in Dominican hairdressing salons in Santiago de Chile}

Recibido el 1 de diciembre de 2019. Aceptado el 13 de mayo de 2020. Publicado el 15 de mayo de 2020.

*Autora para correspondencia: Antonia Lara. Correo electrónico: alara@ucsh.cl

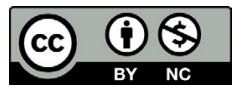

Esta obra está protegida bajo una Licencia Creative Commons Atribución-NoComercial 4.0 Internacional.
Antonia Lara ${ }^{\text {a* }}$ (D) https://orcid.org/0000-0002-3530-4763

${ }^{\text {a } U n i v e r s i d a d ~ C a t o ́ l i c a ~ S i l v a ~ H e n r i ́ q u e z ~(U C S H), ~ C e n t r o ~ d e ~ I n v e s t i g a c i o ́ n ~ e n ~ C i e n c i a s ~ S o c i a l e s ~ y ~}$ Juventud (cISJu), Santiago, Chile, correo electrónico: alara@ucsh.cl

\section{Resumen}

El propósito de este artículo es aportar al campo de estudio sobre configuración de identidades en contextos migratorios, por medio de la búsqueda de prácticas cotidianas realizadas en las peluquerías en Santiago de Chile. Lo anterior se llevó a cabo a través de una indagación etnográfica durante 18 meses (años 2015 y 2016). Se obtuvo que el espacio de la peluquería se organiza en torno a las prácticas del alisado del cabello afro y el llamado brushing dominicano, las que, junto a maneras de usar la peluquería, generan pertenencia y, al mismo tiempo, diferencias y jerarquías entre mujeres, producidas en la interseccionalidad entre nacionalidad, género y "raza". Desde la peluquería como intento de lugar propio, se generan disputas, resistencias y transacciones con el contexto local. Una limitación del presente artículo es no dar cuenta de la perspectiva masculina, de sus prácticas y concepciones respecto al trabajo de belleza del cuerpo.

Palabras clave: migración dominicana, género, etnografía, prácticas cotidianas, identidad, interseccionalidad.

\begin{abstract}
The purpose of this article is to contribute to the field of study on identity configuration in migratory contexts, by investigating daily practices carried out in hairdressing salons in Santiago de Chile. The above was carried out through ethnographic research for 18 months (2015 and 2016). It was obtained that the hairdressing space is organized around the practice of Afro hair straightening and the so-called Dominican brushing, which together with ways of using the hairdressing salons, generate belonging and, at the same time, differences and hierarchies between women, produced in the in-
\end{abstract}

CÓMO CITAR: Lara, A. (2020). Configuración de identidades en contextos migratorios: indagación de prácticas cotidianas en peluquerías dominicanas en Santiago de Chile. [Configuration of identities in migratory contexts: investigation of daily practices in Dominican hairdressing salons in Santiago de Chile]. Estudios Fronterizos, 21, e049. https://doi.org/10.21670/ref.2007049 
tersectionality between nationality, gender and "race". From the hairdressing salon as an attempt at their own place, disputes, resistance and transactions are generated with the local context. A limitation of this article is not to account for the male perspective, its practices and conceptions regarding the beauty work of the body.

Keywords: Dominican migration, gender, ethnography, daily practices, identity, intersectionality.

\section{Introducción}

El presente artículo busca aportar al campo de estudio sobre configuración de identidades en contextos migratorios, por medio de la indagación de las prácticas cotidianas que se realizan en las peluquerías internacional-dominicanas de un barrio de la comuna de Estación Central, en Santiago de Chile. Lo anterior, forma parte de una investigación doctoral finalizada, ${ }^{1}$ sobre la configuración de subjetividades de mujeres dominicanas en Santiago, desde dichos espacios.

Al seguir a Candelario (2000) se concibe el espacio de las peluquerías dominicanas como relevante para el estudio de las subjetividades femeninas, en la medida en que "es una ventana a la complejidad de la identidad dominicana (...), donde las mujeres aprenden a transformar sus cuerpos en una imagen de la feminidad valorada socialmente, con especificidad cultural y racialmente determinada" (p. 135). En estos espacios se produce un sentido de pertenencia que, como señalan Mansilla e Imilán (2018), en su artículo sobre peluquerías afrocaribeñas en el centro de Santiago de Chile, se ponen en práctica y expresan en los cuerpos: "[1] os migrantes portan territorio, comunicando sentidos de pertenencia a través de la expresividad de sus cuerpos" (Mansilla \& Imilán, 2018, p. 254). Sin embargo, en el contexto migratorio, la peluquería dominicana no se constituye como una reproducción de las prácticas de "origen", sino que desde ahí se producen diferencias con el contexto local. Es decir, en tanto espacio de contacto entre prácticas socioculturales diversas, conforman un "tejido contaminado pero conectivo" (Bhabha, 2010), donde se dan disputas, resistencias y transacciones con las prácticas de belleza locales y sus marcos de valoración respecto al cuerpo de la mujer.

Los resultados que aquí se presentan se obtuvieron por medio de la inmersión etnográfica (Velasco \& Díaz de Rada, 1997) en la vida cotidiana de las peluquerías dominicanas en un barrio de la comuna de Estación Central, emplazado en la avenida Libertador Bernardo O'Higgins (Alameda), en Santiago de Chile. La pregunta con la que se enfrentó el trabajo de campo fue ¿Cómo son las prácticas cotidianas que se realizan en las peluquerías dominicanas de Estación Central y cuáles sus significaciones? De tal manera, se buscó realizar un relato etnográfico denso (De la Torre, 2018) que supone la traducción de una práctica, de sus significados, códigos y valores.

Las preguntas abordadas a partir de las prácticas cotidianas exploradas en las peluquerías "internacional-dominicanas", consideradas como espacios donde se construyen procesos de identidad y diferenciación de mujeres dominicanas en Chile, resultan relevantes en la medida en que aportan con conocimiento empírico de

\footnotetext{
1 Una versión preliminar de los resultados de investigación fue presentada en las VIII Jornadas de Investigación en Antropología Social "Santiago Wallace" (2016). http://iiassw.filo.uba.ar/
} 
primera fuente a los estudios sobre mujeres migrantes afrodescendientes en Chile, habitualmente excluidas e invisibilizadas. Asimismo, aporta al campo de estudios sobre identidades de género, etnoraciales y nacionales en las migraciones internacionales, desde la discusión sobre las prácticas cotidianas y socioculturales vinculadas a la belleza, el cuerpo y, específicamente, el cabello como objeto. A la vez que resulta un aporte analizar las maneras de decir, como una vía de indagación sobre las transacciones y resistencias como marcas subjetivas que operan en el ámbito de las problemáticas identitarias, en contextos de migración latinoamericana.

En la primera sección, el artículo expone los antecedentes de la migración dominicana a Chile. Lo anterior refiere tanto a la emigración de mujeres dominicanas a sus principales destinos: España y Estados Unidos, así como de la inmigración dominicana a Chile desde el año 2010. La segunda sección trata de los debates conceptuales sobre peluquerías dominicanas entendidas como lugares de producción identitaria en contexto migratorio, y sobre la noción de identidad nacional y de género, así como de las prácticas cotidianas, entendidas como tácticas y estrategias que realizan los inmigrantes en la ciudad, sus espacios y lugares. En la tercera sección se exponen los resultados de la investigación etnográfica. A su vez, esta sección se divide en tres apartados, en el primero se describen las peluquerías "internacionaldominicana" de un barrio de la comuna de Estación Central en Santiago. En el segundo apartado se analiza la frase "La peluquería es como la embajada de nosotros, el lugar en que te sientes como en casa”, para describir el modo en que opera como estrategia identitaria. Y en el tercer apartado, se analiza la denominación de las peluquerías como "internacional-dominicanas", en tanto espacios de disputa, resistencias y transacciones con lo local, a través de las tácticas que se utilizan en el proceso de relocalización de las peluquerías dominicanas en Santiago de Chile. Finalmente, en la última sección se plantean las conclusiones del artículo.

\section{Antecedentes de la migración dominicana a Chile}

\section{Emigración dominicana de mujeres}

La historia de migración internacional de República Dominicana es de larga data. Expertos en el tema (Tejeda, 2016; Alcalde, 2011; Sorensen, 2005; Bissainthe, 2003) convergen en identificar que la salida masiva de dominicanos se produjo durante la recesión económica de la década de 1980. En la actualidad, según el Perfil Migratorio de República Dominicana (Organización Internacional para las Migraciones [orm], 2017), la emigración de dominicanos y dominicanas equivale a cerca de $20 \%$ (incluidos descendientes) de la población de dicha nacionalidad. Como se señala, los principales destinos de la emigración dominicana han sido Estados Unidos, Puerto Rico y España. Y los patrones de migración internacional, desde mediados de la década de 1990, se han mantenido relativamente constantes hasta la actualidad, es decir, se trata de "un país principalmente emisor de migrantes por motivos económicos, que a su vez presenta una alta inmigración laboral" (oIM, 2017, p. 59), proveniente mayoritariamente de Haití.

Respecto a la migración de mujeres dominicanas a Estados Unidos, se ha señalado que inicialmente estaba conformada por clases medias calificadas que salieron del país durante la dictadura de Trujillo y del gobierno de su continuador, José Antonio 
Balaguer (Bissainthe, 2003). Las mujeres que emigraban, en esos años, lo hacían en calidad de "esposas acompañantes" (Sorensen, 2005) y no como parte de un proyecto propio. En cambio, la emigración masiva que se dio a partir de la crisis económica de los años de 1980 "afectó a casi a todas las capas sociales, especialmente las clases campesinas, debido al colapso de la economía rural" (Bissainthe, 2003, p. 141). En este segundo flujo se produce una variación en el liderazgo del proceso, ya que la migración femenina tendría esta vez un carácter de proyecto propio para las mujeres que buscaron con su salida opciones de trabajo asalariado (Alcalde, 2011). Es este segundo flujo de mujeres dominicanas, el que habría emigrado mayoritariamente a España.

Según diversos autores (Alcalde, 2011; Ariza, 2012; Gregorio, 1998; Sorensen, 2005, 2006) el elevado componente femenino del flujo dominicano a España en los años de 1990, era un "rasgo que la singulariza en el concierto más amplio de las naciones latinoamericanas" (Ariza, 2012, p. 16) en dicho país. Así, se caracterizaba por mujeres que asumían "cada vez más un papel protagonista" (Sorensen, 2005, p. 164) en su migración, proceso que ha sido explicado en función del trabajo disponible para mujeres inmigrantes en el ámbito de servicios.

Según el Perfil migratorio de República Dominicana (оIM, 2017), los patrones actuales de feminización de los flujos migratorios de ese país pueden explicarse en parte por el índice de desigualdad de género, es decir, "por el riesgo a la discriminación y la violencia por motivos de género que enfrentan” (p. 71) las mujeres en el país. Así como por factores externos, tales como las crisis económicas y el endurecimiento de las políticas migratorias en los países de destino históricos de la migración dominicana (OIM, 2017).

\section{Inmigración dominicana de mujeres a Chile}

Chile, por su parte, se constituyó tras el retorno a la democracia (finales de la década de 1990), por su estabilidad económica y política, en polo de atracción de inmigrantes. Así, al comienzo de la democracia, empezaron a llegar flujos de personas provenientes de países limítrofes como Perú, Bolivia y Argentina. Dentro de este flujo destacó la inserción de las mujeres peruanas en el trabajo doméstico. Lo anterior se explicaba por la constitución de nichos de trabajo específico para la migración femenina, en “(...) actividades consideradas como 'de mujeres inmigrantes', cuyo caso emblemático lo constituyen el trabajo doméstico y el comercio” (Mora, 2008, p. 289). Posteriormente, desde 2010, se comenzó a incrementar el flujo de personas provenientes de Colombia, República Dominicana y Haití. Una diferencia de estos colectivos presentes en Chile respecto a los anteriores fue que muchos de aquellos eran afrodescendientes, de modo tal que su fenotipo los distinguía como inmigrantes en la sociedad chilena donde la afrodescendencia no ha sido de las principales características de la población.

En relación con la migración dominicana se ha identificado que a partir del cierre de fronteras en Estados Unidos y la crisis económica en España se diversificaron sus destinos dentro de la región latinoamericana, para llegar, en los últimos años, a Argentina, Uruguay y Chile (Galaz et al., 2016). Si bien la inmigración dominicana había sido poco destacada cuantitativamente en el país, a partir de 2010 comienza a aumentar (Galaz et al., 2016) y se caracteriza por su tendencia notoriamente femenina, ya que $70 \%$ estaba constituido por mujeres (Galaz et al., 2016). Frente 
al incremento de la inmigración dominicana, el Estado chileno aplicó en 2012 una medida restrictiva a través del requisito de visa consular, con la cual se buscó disuadir la entrada de extranjeros no deseados (Bravo, 2015). Sin embargo, esta iniciativa no tuvo el efecto esperado, ya que se produjo una baja "artificiosa" en las estadísticas migratorias: se otorgaron menos permisos, pero las personas siguieron entrando al territorio nacional por pasos no habilitados (Galaz et al., 2016). Al respecto, en el Boletín Informativo del Departamento de Extranjería y Migración se expresa que "resultan preocupantes los niveles de vulnerabilidad en que se encuentran aquellas mujeres en situación irregular, al haber llegado a través de redes de tráfico de personas por pasos no habilitados" (Galaz et al., 2016, p. 17). Así, muchas personas de nacionalidad dominicana han quedado en una situación migratoria indocumentada, con lo que aumenta el mercado informal de trabajo.

En relación con el asentamiento del colectivo dominicano en Chile, este se produjo preferentemente en la capital nacional, Santiago, donde se insertan en trabajos de baja calificación del ámbito de servicios y comercio, así como de autoempleo en "emprendimientos en temas de belleza, vestimenta, peluquería" (Galaz et al., 2016, p. 13-14). En relación con las peluquerías, estas se concentran, como otros comercios de inmigrantes (Garcés, 2011), tanto en la comuna del centro de Santiago, como en la comuna pericentral de Estación Central.

\section{Debates conceptuales}

\section{Peluquerías dominicanas como lugares de producción identitaria en contexto migratorio}

La peluquería dominicana ha sido estudiada en el contexto de la migración de este colectivo a la ciudad de Nueva York, así como a Puerto Rico. Autoras como Candelario (2000, 2007) y Amezquita (2010), se han aproximado a estos espacios considerándolos no solo como un ámbito de empleo flexible para las mujeres, sino también como un lugar de pertenencia y reproducción de la cultura e identidad dominicana. Ambas coinciden en señalar que los salones dominicanos representan "Un importante agente socializador que facilita la adaptación de inmigrantes y transmigrantes a la ciudad de Nueva York, ya que les permite sostener las identidades etno-raciales dominicanas como indohispánicas" (Candelario, 2007, pp. 28-29). Para Quiñones (2007) y Godreau (2002), en cambio, la peluquería se constituye como un espacio femenino, en el que, hasta cierto punto, las interacciones que allí ocurren permiten la emancipación de las mujeres de las restricciones que experimentan en su vida diaria (Quiñones, 2007). En la misma línea, Godreau señala que en el salón de belleza "hay un tiempo compartido y de contacto íntimo entre mujeres que se dejan tocar, halar y lavar por otras, ya sea a cambio de un pago o simplemente porque sí" (Godreau, 2002, p. 121). De modo que en estos espacios proveen más bien de un cierto alivio temporal de las presiones y restricciones que recaen sobre las ellas.

Amezquita (2010), por su parte, ha estudiado las peluquerías en el contexto de migración como lugares donde se crea una sensación de comunidad y socialización, en el que las mujeres dominicanas pueden sentir pertenencia y, en ese sentido, aceptación por su cultura. Mientras que Candelario (2007) se preguntaba cómo las normas 
dominicanas de belleza —entendidas en clave nacional y racial—, interactúan con las estadounidenses en las peluquerías dominicanas. Al respecto, señala que para los dominicanos identificarse como hispanos, tanto en Estados Unidos como en República Dominicana, les ofrece la alternativa a ser reconocidos como "negros", ya que hispano constituye una categoría racializada que es no-blanco y también no-negro (Candelario, 2000). A partir de estas aportaciones, nos propusimos indagar en las peluquerías dominicanas de Estación Central ¿Qué función tiene la peluquería dominicana para las mujeres que allí concurren? ¿Qué prácticas cotidianas caracterizan el espacio de la peluquería dominicana en Estación Central y cuáles son sus ideales de belleza? y ¿Cómo interactúan aquellas con los ideales de belleza imperantes en Santiago?

\section{Identidades etnonacionales, raciales y de géneros en las prácticas cotidianas}

Como se ha visto en las investigaciones mencionadas, la peluquería en el contexto migratorio se considera como un espacio que provee pertenencia en el contexto migratorio, en función del despliegue de una cierta identidad.

Ahora bien, hay que considerar aquí la noción de identidad desde una perspectiva crítica que pone de relieve su carácter ideológico (Laclau, 1993; Hall, 2003). Las identidades constituyen

(...) formas discursivas a través de las cuales la sociedad trata de instituirse a sí misma sobre la base del cierre, de la fijación del sentido, el no reconocimiento del juego infinito de las diferencias. Lo ideológico sería la voluntad de "totalidad" de todo discurso totalizante (Laclau, 1993, p. 20).

En una línea similar, Hall (2003) pone de relieve que la unidad y homogeneidad que supone una identidad no tiene un carácter natural sino construida en relación con otro, en tanto "(...) toda identidad nombra como su otro necesario, aunque silenciado y tácito, aquello que le 'falta"' (Hall, 2003, p. 19). Es decir, se trata de su afuera constitutivo en la medida en que la identidad se constituye en relación con una diferencia, “(...) actúa a través de la diferencia, entraña un trabajo discursivo, la marcación y ratificación de límites simbólicos, la producción de 'efectos de frontera'. Necesita lo que queda afuera, su exterior constitutivo, para consolidar el proceso" (Hall, 2003, p. 16). De tal modo, la noción de identidad con la que se trabajó refiere a prácticas discursivas (Foucault, 2001) que se utilizan de manera estratégica y posicional (Hall, 2003).

Por su parte Butler (2005), en la crítica que desarrolla respecto al esencialismo identitario, plantea que las identidades de género no se constituyen de manera estable, “(...) nunca se construyen plena y definitivamente; se reconstituyen de manera incesante y, por eso, están sujetas a la volátil lógica de la iterabilidad” (p. 159). Es decir, no hay una "sustancia constante" que las defina, sino que se constituyen en la repetición.

Ahora bien, desde los estudios postcoloniales la identidad nacional es concebida como constituida por "maniobras ideológicas, mediante las cuales se dota a las 'comunidades imaginadas' de identidades esencialistas" (Bhabha, 2010, p. 396), las cuales se traducen como costumbres, idiosincrasias, valores patrios, etcétera. A la 
vez que, en dichas maniobras, como señala Segato (2007), "generan otredad", en tanto "representaciones hegemónicas de nación (...)" (Segato, 2007, p. 29). Estas representaciones constituyen ideales sociales y culturales, a los cuales debieran adherir los individuos. Aquellos ideales que generan identificación y pertenencia no operan de modo neutro, es decir, no tienen todos ellos el mismo valor social, sino que en tanto están cruzados por dimensiones de poder, se organizan jerárquicamente.

Del mismo modo, las relaciones de género se constituyen desigualmente. Desde el campo de estudios de migración y género, se ha puesto de relieve el modo en que estas desigualdades están en la base de las dinámicas migratorias (Mora, 2008), del modo en que se estructuran (Barral Mallimaci, 2011) y de sus prácticas sociales (Oso \& Parella, 2012).

Respecto al ámbito de prácticas sociales que aquí se estudian, los trabajos de arreglo del cuerpo y de belleza (Arango, 2011; Candelario, 2000) de las peluquerías, ponen en práctica concepciones e ideales culturales respecto al género. En esta línea Arango (2011) señala que los “(...) mandatos culturales se ejercen de manera diferenciada sobre hombres y mujeres, siendo estas últimas las principales destinatarias de los imperativos estéticos" (Arango, 2011, p. 6), que constituyen el cuerpo femenino como "cuerpo para otro". Como señala Butler (2017), lo que hace existir a un cuerpo es la perspectiva de los demás: "[y]o existo, en tanto que cuerpo, (...), ni siquiera en primera instancia para mí mismo, sino que (...) mi cuerpo se establece por medio de perspectivas que no puedo habitar, pero que seguramente sí habitan en mí" (Butler, 2017, p. 81). De tal manera, los trabajos de peluquería y belleza para mujeres, conceptuados como servicios personales de trabajo corporal y emocional (Arango, 2011), están dirigidos a mostrar cómo se acerca la imagen del cuerpo al ideal sociocultural de la feminidad (Tubert, 2010).

Es así como en el ámbito de los ideales socioculturales que se ponen en práctica en el espacio de las peluquerías, la categoría de género no se puede considerar de manera aislada ya que, como señala Magliano (2015), en tanto las clasificaciones sociales se producen de manera articulada, es necesario "pensar al género como etnizado, siempre racializado, siempre influido por la clase y así sucesivamente" (Magliano, 2015, p. 697). Es decir, en intersección con otras categorías que perpetúan desigualdades que funcionan por medio de relaciones íntimas, recíprocas y contradictorias entre ellas (McClintock, 1995).

En el contexto latinoamericano, los procesos de migración femenina van unidos “[a] la percepción de que los imaginarios que racializan y marginan a los migrantes atraviesan fronteras y tienen, frecuentemente, un impacto más fuerte sobre las mujeres migrantes" (Guizardi et al., 2018, p. 47). De modo que la perspectiva interseccional permite comprender la posición social de las mujeres migrantes como producto de " $[u]$ n complejo engranaje de poder en el cual existen estructuras de discriminación que las presionan de forma múltiple y simultanea" (Cea-Merino et al., 2015, p. 36), produciendo identidades situadas y temporales según contextos de migración.

De tal manera, las producciones identitarias en contextos de dislocación y extrañamiento no implican necesariamente fijaciones a una posición subjetiva, por el contrario, caracterizan muchas veces luchas por la identidad (Bartkowski, 1995) que se ponen en juego en las prácticas socioculturales cotidianas. Entendemos las prácticas socioculturales cotidianas como "sistemas de valores subyacentes que estructuran las cuestiones fundamentales que están en juego en la vida cotidiana, inadvertidas a través de la conciencia de los sujetos, pero decisivas para su identidad individual y de grupo" 
(Mayol, 1999, p. 7). Así, las identidades implican una localización social desde donde enunciarse y disputar, asociarse y negociar o tranzar con otros, constituyendo el "arte de la guerra cotidiana" (De Certeau, 1996b, p. 44). En esta concepción "polemológica" de la vida cotidiana, como lo denomina De Certeau (1996b), se distinguen las estrategias de las tácticas. Respecto a las primeras, las entiende como “(...) un tipo específico de conocimiento, que sustenta y determina el poder de darse un lugar propio, (...) una victoria del lugar sobre el tiempo, en la medida en que permite capitalizar las ventajas adquiridas" (De Certeau, 1996b, p. 43). Mientras que las tácticas, constituyen "maneras de moverse en el campo del otro aprovechando las ocasiones (...), instauran algo de la pluralidad y la creatividad. Gracias a un arte de intervalo" (De Certeau, 1996b, p. 36). Así las tácticas permiten la movilidad, se trata de una apuesta sobre el tiempo, mientras que, en las estrategias, una apuesta sobre el lugar.

A su vez, con referencia al tiempo, el autor pone en relación la noción de espacio con las tácticas, al decir que:

(...) el espacio es un lugar practicado (...) es un cruzamiento de movilidades. Está de alguna manera animado por el conjunto de movimientos que ahí se despliegan. Espacio es el efecto producido por las operaciones que lo orientan, lo circunstancian, lo temporalizan (...) A diferencia del lugar, carece pues de la univocidad y de la estabilidad de un sitio 'propio' (De Certeau, 1996a, p. 129).

De tal modo, en situación de migración los sujetos echan mano de tácticas y estrategias que les permiten moverse en el campo del Otro, encontrando desvíos y atajos en el "orden imperante", en los cuales utilizan las identidades (o un aspecto de ellas) a su favor. A la vez que hacen propios ciertos espacios, a través de los modos en que practican la cultura.

\section{Metodología}

La indagación se llevó a cabo por medio de la inmersión etnográfica (Velasco \& Díaz de Rada, 1997) en el espacio de las peluquerías internacional-dominicanas de Estación Central. Así, desde la perspectiva de la vida cotidiana (De Certeau, 1996b; Reguillo, 2000) se realizó observación participante de las prácticas que se dan en estas peluquerías, maneras de hacer y de decir (De Certeau, 1996b), de mujeres dominicanas en Santiago de Chile.

El trabajo de campo tuvo una duración de 18 meses (entre los años 2015 y 2016) y se realizó en tres peluquerías, ubicadas en una zona de veinte cuadras donde se podía encontrar una decena de ellas. En el grupo de peluquerías donde se realizó la etnografía están las de Juan y Raquel, ${ }^{2}$ de los relatos etnográficos de las prácticas cotidianas de dichas peluquerías se han extraído fragmentos que aquí presentamos.

En la indagación se utilizaron guías de observación sobre las prácticas cotidianas y de arreglo del cuerpo de las mujeres en las peluquerías, así como entrevistas realizadas en la misma peluquería a algunas mujeres, a dueños y dueñas de peluquerías, así como peluqueras, clientas habituales (aquellas que asistían cada semana) y aquellas

\footnotetext{
${ }^{2}$ Se utilizan nombres ficticios.
} 
que pasaban como visitas de manera regular. En el momento del trabajo de campo, las edades de las mujeres fluctuaban entre los 19 y los 50 años, y tenían distintos años de migración a Chile. Raquel, por ejemplo, tenía dieciséis años viviendo en Chile, mientras que Juan llevaba solo dos años. Entre las clientas y visitas de la peluquería, la mayoría tenía entre dos y cuatro años en Chile, y se dedicaban a trabajos en el ámbito de servicios doméstico y de atención al público. Una menor cantidad de mujeres en las peluquerías tenían pequeños negocios de venta de productos (dominicanos y otros) o de servicios, y excepcionalmente había quienes eran profesionales con estudios superiores universitarios o técnicos.

\section{Resultados}

\section{Las peluquerías "internacional-dominicana" de Estación Central}

En la capital de Chile, Santiago, la comuna central del mismo nombre es la que concentra la mayor cantidad de inmigrantes (21\% respecto a su población), seguida por las comunas pericentrales de Independencia (19,7\%), Estación Central (11,5\%) y Recoleta $(9,1 \%)$ (Instituto Nacional de Estadísticas de Chile [INE], 2018). Estas tres comunas constituyen una "macrozona centro" que "abarca $45 \%$ de los inmigrantes del país" (Atisba Monitor, 2018, p. 9).

No resulta casual que esta comuna concentre la residencia de inmigrantes latinoamericanos, toda vez que históricamente fue la puerta de entrada a la capital a través de la principal estación de ferrocarriles del país. En efecto, la Estación Central de Santiago fue construida a finales del siglo xix y era paso obligado de la inmigración rural que llegaba a trabajar a la capital. Actualmente, la estación de trenes mantiene un servicio limitado, el cual conecta a la capital solo con zonas rurales aledañas, que es utilizado principalmente por trabajadores y estudiantes.

Desde la estación de trenes, avanzando por la avenida Libertador Bernardo O'Higgins (Alameda) — principal arteria de la capital— hacia el poniente, en un territorio de unas veinte cuadras, se encuentran alrededor de diez salones de belleza dominicanos, los cuales son reconocibles por la bandera en sus letreros.

Si se consideran los locales comerciales de esta zona - restaurantes, negocios de abarrotes y centros de llamados-, como indicativo de las nacionalidades de quienes viven y trabajan en el sector, se puede deducir que, además de la población dominicana, hay presencia de personas provenientes de Perú y Colombia. Al caminar por la vereda sur de la avenida Alameda se pueden observar diversos locales comerciales, entre ellos uno de cervezas y comida peruana llamado Cevichería y otro de pollo a las brasas, más conocido como La Shoppería. Junto a este local se ubica El flow peluquería internacional, el cual está compuesto por dos locales cuyo frontis destaca por sus azulejos de colores rojo y negro. Se trata de una cadena de peluquerías dominicanas orientada a público masculino, mayoritariamente afrodescendientes. Estos locales tienen habitualmente gran flujo de clientela, quienes se ubican dentro y fuera del local, en la vereda, mientras esperan a ser atendidos, conversan y escuchan música bachata o reggaetón. A dos cuadras de El flow, se encuentra la peluquería de Raquel ubicada en el primer piso de un conjunto de edificios de mediana altura, construido en la década de 1990. El local de Raquel se encuentra junto a la puerta de entrada 
del conjunto de edificios, por lo tanto, hay gran circulación de personas que entran y salen del inmueble, en uno de cuales vive ella y otros dominicanos y dominicanas que van a peinarse, a saludar o a conversar en su peluquería.

$\mathrm{Al}$ igual que en la peluquería El flow y otras del sector (peluquería de Francisca y de Juan), la de Raquel se anuncia con un letrero que luce la bandera dominicana y con el nombre: "Salón de belleza y peluquería. Raquel. Internacional-dominicana". Al preguntarle a Raquel sobre el uso de los términos "salón de belleza" y "peluquería", ella señala que es para tener las dos maneras con que se nombran: el primero en República Dominicana y el segundo en Chile, y así atraer clientela de ambos países. Asimismo, respecto a los términos "internacional" y "dominicana" ella señala que "ya estamos fuera de mi país y traemos un estilo de corte y peinado del cabello que es internacional". El uso del término refiere tanto a traer un estilo de "fuera", como a que la propia peluquería está "fuera" de su país y, por tanto, no podría denominarse "puramente" dominicana. De modo que, en un uso estratégico del término "internacional", Raquel busca desnacionalizar en parte la referencia, y de ese modo no cerrar las fronteras de su peluquería solo a la clientela dominicana, ya que sabe que de ese modo no se sostiene como negocio.

En las observaciones realizadas en las peluquerías del sector, durante los días de semana la afluencia de público es baja (cinco personas diarias aproximadamente), y la clientela varía entre hombres de nacionalidad chilena o peruana y señoras chilenas, adultas mayores del sector. Como explicaba Juan, "los hombres dominicanos no se cortan en el salón de mujeres, sino en los de hombres dominicanos" como la peluquería El flow. De tal modo, aun cuando las peluquerías no especifican si son femeninas, masculinas o "unisex" (es decir que ofrecen servicios para ambos), como suelen anunciarse las peluquerías chilenas, entre las personas dominicanas "se sabe" que en su mayoría los hombres dominicanos no utilizarán las peluquerías orientadas a público femenino.

Raquel explica que el negocio de la peluquería "tiene sus temporadas", con días de muy poca clientela y épocas del año en que bajan mucho los ingresos: "A veces no alcanza, porque Santiago no es Nueva York y vivir aquí es caro". La evaluación del negocio de la peluquería como inestable económicamente hacía que sus dueñas y dueños estuvieran constantemente evaluando la conveniencia de mantener los salones abiertos, o bien cerrarlos y emplearse como peluqueras en otros establecimientos. En efecto, durante los casi dos años en los que se realizó el trabajo de campo en la zona en estudio, algunos de los salones visitados cerraron, cambiaron de dueña y también se abrieron nuevas peluquerías. Se trata pues, de un negocio que en ocasiones no logra sostenerse en el tiempo, ni capitalizar sus ganancias. A pesar de lo anterior, Raquel explica la proliferación de estas peluquerías en que "algunas mujeres trabajan en casas tres años y cuando les dan la [visa] definitiva se van a trabajar a peluquería. Es que en las casas las explotan mucho por pocos chelitos". ${ }^{3}$ Para Juan, en cambio, lo anterior se explica en que "hay un boom de las peluquerías dominicanas en Chile, porque no es difícil instalar una y todo el que viene de dominicana sabe pasar el blower".

Respecto a la inmigración dominicana, Raquel relataba el cambio que significó la visa consultar implementada por el Estado chileno:

\footnotetext{
${ }^{3}$ Modo de nombrar el dinero, utilizado por las mujeres dominicanas en la peluquería.
} 
En ese tiempo no se necesitaba visa, la mayoría trabajaba de nana ${ }^{4}$ y también había médicos y profesionales. Como el flujo se puso tan fuerte se cerró la puerta (...). Ahora llega mucha gente ilegal, los traen engañados, sin papeles, hay mucha gente entrando 'por el hoyo'.

En esta explicación, Raquel recurre a una expresión muy utilizada por las mujeres dominicanas en las peluquerías: "entrar por el hoyo", la cual refiere a la entrada clandestina al país, por medio de redes de tráfico de personas:

Les cobran por traerlos, les dicen que le tienen los papeles y es falso. En el camino, por tierra desde Ecuador o Perú, les cobran más y a veces los dejan botados y les quitan sus cosas. Les dicen que tienen que entrar caminando por el desierto y recién ahí se dan cuenta que van a entrar ilegales.

Este tema se observó en las conversaciones en las peluquerías, donde las mujeres se manifestaban preocupadas por saber cómo regularizar su situación migratoria en Chile, cuáles eran los trámites necesarios para obtener visa, para traer a los hijos o para formalizar su condición como trabajadoras inmigrantes. De modo tal, la peluquería funcionaba para ellas como un espacio donde ir a buscar consejos acerca de cómo solucionar sus problemas de documentación migratoria, lo que da sentido, en parte, a la frase de Raquel: "Vienen aquí las clientas antiguas o las personas que necesitan orientación. Dicen que soy la embajada chica".

\section{"La peluquería es como la embajada de nosotros, el lugar en que te sientes como en casa"}

En las visitas a las peluquerías dominicanas del mismo barrio, en repetidas ocasiones fue explicada la importancia de la peluquería tanto para mujeres como para hombres dominicanos por medio de la frase de Juan: "la peluquería es como la embajada de nosotros". En una ocasión, un muchacho dominicano recién llegado a Santiago que estaba en la peluquería de Juan declaró:

Sí, es que la peluquería es como la embajada de nosotros, el lugar en que te sientes como en casa, donde ponen la música de tu país, comen la comida de tu país y hablan de lo que pasa allá.

Así, no se alude a la peluquería solamente como el lugar donde se puede acceder a información y atajos para realizar trámites migratorios, sino que está asociada con aquellas prácticas cotidianas: maneras de preparar la comida, maneras de peinarse y alisar el cabello, la música que se acostumbra a escuchar y las maneras de decir, con las que se identifican. $\mathrm{Y}$, en tanto aquellas prácticas las vincula a su vida cotidiana en República Dominicana, es significado como estar y sentirse "en casa".

De tal manera, en la metáfora de la peluquería como la embajada, y la embajada como la casa, se trata de un espacio que por momentos se siente como territorio dominicano, en tanto espacio de prácticas identificadas como las propias de esa nación. Lo anterior, le permitía a él sobrellevar su vida en Santiago: “(...) es difícil

\footnotetext{
${ }^{4}$ Modo de referirse a la mujer trabajadora doméstica en Chile.
} 
estar solo acá, es un sacrificio estar comiendo a deshora, cosas que no son las que tú estás acostumbrado, pasando frío, sin ver a tu familia”. La constitución de estos espacios de prácticas nacionalizadas las interpretamos como una estrategia que permite restituir, al menos mientras están ahí, una sensación de continuidad identitaria que, en ocasiones, se ve amenazada en el tránsito migratorio. Así, cumple la función de proveer de un cierto alivio en su vida cotidiana como mujeres y hombres migrantes de baja calificación en Santiago.

Ahora bien, a pesar de ser un espacio donde se comparten maneras "dominicanas" de practicar la cultura, lo que les permite hacerse de un "lugar propio" (De Certeau, 1996b), las peluquerías dominicanas en Estación Central tienen una estabilidad precaria, por tanto, es relevante resaltar que se trata de un intento y que opera de modo fluctuante.

Ahora bien, respecto a aquellas prácticas cotidianas que, los y las hacen sentir como "en casa", se trata del modo en que las mujeres dominicanas ocupan el espacio de la peluquería. Los días sábado en que las peluquerías solían estar muy concurridas en las tardes, cuando las mujeres salían de sus trabajos y su clientela era mayoritariamente de mujeres dominicanas, había ocasiones en que, a primera vista, no resultaba evidente quiénes eran las peluqueras y quiénes las clientas. Así, se podía observar a alguna de las mujeres con rollos en la cabeza, es decir, con apariencia de clientas, que estaba peinando a otra mujer. Ello, porque muchas de las mujeres dominicanas que van como clientas a las peluquerías también saben — sin necesidad de tener estudios especializados-, lavar y peinar con secador de pelo o blower. Como lo explicaba Juan, "todo el que viene de dominicana sabe pasar el blower, porque se peinan unas con otras en los patios de las casas", haciendo referencia a las llamadas "peluquerías de patio" las cuales, señala Candelario (2000), "Son locales que estaban ubicados típicamente en una pieza delantera o patio de la casa acondicionada como peluquería" (Candelario, 2000, p. 132).

Así, aun cuando peluquerías como la de Raquel o Juan estuvieran ubicadas en locales comerciales sobre la avenida Alameda, se podía observar esta escena de mujeres peinándose mutuamente como si estuvieran en el patio de la casa. De este modo, mientras algunas mujeres tomaban cerveza, otras miraban su celular o comían plátano maduro, una contaba a las demás el problema que había tenido en el trabajo o con el marido y las mujeres le daban su parecer o consejos, mientras otras dormitaban bajo el secador de pelo.

La mayoría de las conversaciones colectivas en la peluquería ocurrían en un volumen de voz que a ratos daba la impresión de que fueran gritos de una pelea, mientras la tonada de algún bachatero famoso se escuchaba en los silencios de las conversaciones. En suma, se puede decir que lo observado allí hacía pensar en un espacio público (un negocio de venta de servicios de belleza) íntimo (en el patio interior de una casa) a la vez, donde un grupo de amigas se reúne a lavarse y peinarse el cabello "unas con otras".

Otro aspecto del modo en que ocupan el espacio de las peluquerías que las hace sentir como "en casa" es respecto a las conversaciones y las maneras de decir, entendidas como los “(...) modos de habitar una lengua” (De Certeau, 1996b, p. 36). Lo anterior refiere tanto a los modismos, como a las maneras de usar las palabras, a sus entonaciones y acentos del habla en los que opera una cierta identificación nacional. Esto resulta así, al entender el acento del habla como la puesta en forma de la voz por 
la referencia a la nación, modulando sus tonos en una melodía que suena conocida, ya que se le identifica como la "propia" de una nación. ${ }^{5}$

En la migración entre países de habla hispana, de Centro y Sudamérica en este caso, las diferencias en el modo en el que se usan las palabras, se pronuncian y entonan, enfrenta al inmigrante a la experiencia de no entender ni ser entendido del todo en lo que dice y lo que se le dice. En la vida cotidiana, se le exige que cambie su manera de hablar, que se esfuerce en hablar con las entonaciones del otro local. En cambio, en el espacio de la peluquería, hablar como dominicanos exime de aquel esfuerzo de articular sentidos y descifrar entonaciones. $\mathrm{Al}$ respecto, a lo largo de la investigación en diversas ocasiones se escuchaba la expresión: "Que rico es hablar así, relajando, como en charcha", es decir, hablar con bromas de dobles sentidos, en un espacio compartido entre mujeres. De modo tal, el "relajo" es una función que las mujeres le atribuían a la peluquería, al explicar que se la considera "el relax de nosotros". De tal manera lo expresaba María, cuando explicaba que antes de ir a su trabajo como mesera en un restaurante en el centro de Santiago, pasaba por la peluquería "para beber un chin de café y darme ánimos para bregar con el restaurante. Me río un rato con mi gente y sigo".

Los sábados en la tarde la peluquería solía estar más concurrida y la mayor parte de las mujeres eran dominicanas, quienes llegaban a peinarse o a conversar después de su jornada laboral semanal. En una ocasión, se produjo una conversación a la que estaban atentas la mayoría de las mujeres, y algunos pocos hombres, acompañantes o visitas, presentes en el salón. En esta se discutía si la mujer sentía placer en la relación sexual con el hombre, a pesar de no haber querido tenerla. Al respecto, una de las mujeres afirmaba: " ¡no se siente na!, una solo se mueve pensando en los chelitos". Mientras que otra mujer decía que, aun cuando inicialmente la mujer no haya querido tener relaciones, el roce y los movimientos del cuerpo ya le hacían sentir, lo que explicaba haciendo movimientos pélvicos desde la silla. Esta demostración con el cuerpo causó un estallido de risas y las mujeres presentes asentían o negaban con la cabeza, apoyando una u otra opinión. Esta conversación ocurría en un volumen alto de voz, casi a gritos y con risas, sobre todo cuando alguna de ellas usaba palabras de connotación sexual directa, aun en presencia de la investigadora, la que no pasaba del todo inadvertida. Lo anterior es corroborado por Altagracia, cuando explicaba que las mujeres dominicanas se cuidaban de hablar sobre estos temas frente a personas chilenas, para no ser asociadas a la prostitución: "Nosotras tenemos cuidados con las chilenas porque a veces mal interpretan y creen que las mujeres están en prostitución y eso, pero es que nosotras hablamos más abiertamente de eso".

De tal manera, había momentos en la peluquería, en que se podían "relajar" y hablar como en charcha, sin ser enjuiciadas o identificadas con el estereotipo de la mujer afrodescendiente y caribeña dedicada a la prostitución.

Otro ámbito de prácticas cotidianas que las hace sentir como "en casa" es respecto a las maneras de hacer el alisado del cabello afro, o también llamado "pelo malo" (Godreau, 2002). Esta manera refiere a la forma de peinar el cabello con el denominado brushing dominicano que es significado como "lo más propio de las mujeres dominicanas". Este proceso consiste en el peinado del cabello afro por medio del cepillado con secador de pelo manual, conocido por su nombre en inglés como blower. Así, peinar el cabello es "pasar el blower", aplicando calor en la hebra del cabello

\footnotetext{
${ }^{5}$ Lo anterior ha sido desarrollado en otro artículo publicado (Lara, 2019).
} 
rizado, mientras se estira usando el cepillo con fuerza suficiente para, en ocasiones, hacer lanzar una exclamación de molestia o dolor. Este procedimiento para peinar el cabello afro constituye "un tipo específico de conocimiento, que sustenta y determina el poder de darse un lugar propio" (De Certeau, 1996b, p. 43). Lo anterior, explica el modo en que las mujeres dominicanas usan la peluquería: "las dominicanas no usan el salón para ocasionales cortes de cabello sino para el lavado y peinado semanal" (Candelario, 2000, p. 134), vuelven cada semana para lavarse y peinarse con el brushing dominicano, lo que constituye una práctica ritualizada. ${ }^{6}$ En dicha práctica se trata de marcos de valoración y normativos, es decir, “(...) coagulaciones discursivas de lo que "soy", lo que "no soy", lo que "debo ser" y lo que "no debo ser" (...)" (Bleichman, 2010, p. 13), respecto a lo femenino, que vehiculizan el sentimiento de pertenencia del yo a un "nosotras" desde el cual enunciarse.

Así, a pesar de la consideración del alisado del cabello afro como una práctica de constricción a normas estético-moral (Godreau, 2002) sobre el cuerpo de la mujer, al mismo tiempo, ir a la peluquería es considerado por las propias mujeres como un momento de relajo para ellas. Como señala Rangelova (2013), “(...) las mujeres en las peluquerías dominicanas descansan de las otras presiones y demandas que recaen sobre la mujer, en un lugar donde se obtiene una placentera atención al cuerpo y las emociones" (Rangelova, 2013, p. 110). Ahora bien, en las peluquerías internacionaldominicanas de Estación Central, si bien dichos elementos de atención al cuerpo y las emociones entre las mujeres de las peluquerías están presentes, al mismo tiempo, las relaciones entre ellas no están exentas de diferencias jerarquizadas en términos etnoraciales, nacionales y de clase.

La primera diferencia que se puede identificar es aquella con las mujeres haitianas, en tanto para el grupo de mujeres dominicanas clientas semanales de las peluquerías, se valoraba negativamente el arreglo de las mujeres haitianas, de las cuales se decía: "nunca van a la peluquería y no se arreglan el cabello". Esta valoración negativa no es producto de la migración a Chile de mujeres dominicanas y haitianas, sino que viene con ellas desde República Dominicana.

La inmigración haitiana en República Dominicana se caracteriza por desempeñarse en labores de baja calificación, como son construcción, agrícola y turismo (orm, 2017). Su incremento y situación indocumentada "sigue generando el rechazo de sectores sociales que presionan por el aumento de deportaciones de aquellos a su país" (orm, 2017 , p. 66). Esta apreciación social negativa se alimenta de la historia de disputas territoriales entre países limítrofes en la que se ha plasmado lo que Torres-Saillant (2012) denomina como antihaitianismo, "[u]na actitud de desprecio racial hacia los haitianos, codificada en el término antihaitianismo como ingrediente integral de su idea de nación. Los dominicanos, según dicho razonamiento, se definen negativamente, el antihaitianismo aparece como un componente definidor de la dominicanidad" (Torres-Saillant, 2012, p. 16).

De tal manera, las mujeres dominicanas en las peluquerías consideran a las personas haitianas de manera racializada, en la medida en que Haití representa el lugar de lo "negro puro" (Godreau, 2002), en contraposición a República Dominicana como una nación de carácter hispana (Reyes-Santos, 2008). Lo anterior, y el hecho de que las personas haitianas se ubiquen en trabajos de baja calificación en República

\footnotetext{
${ }^{6}$ Lo anterior ha sido desarrollado en otro artículo publicado (Lara, 2020).
} 
Dominicana, los sitúa en el lugar más bajo de la escala de valoración social para las dominicanas de la peluquería. Esto se podía apreciar en las conversaciones en la peluquería, por ejemplo, cuando una de las clientas contando sus problemas de pareja señaló: "porque yo le dije a él: seré negra, pero no haitiana".

Un segundo orden de diferencias jerarquizadas, derivado de lo anterior, se verifica al interior del grupo de las mujeres dominicanas clientas habituales de la peluquería. Se trata de las diferencias que las mujeres reconocían respecto a las dominicanas con ascendencia haitiana. De manera tal que, después de una conversación grupal en la que María había hecho un chiste aludiendo explícitamente a cómo era tener relaciones sexuales con hombres chilenos, haciendo reír a todas las mujeres presentes en el salón, Raquel explica "es que ella es dominicana, pero su familia es toda haitiana".

Un tercer orden de diferencias jerarquizadas se identificó en relación con las diferencias de clase. Melisa era una mujer dominicana profesional, de cabello y piel clara, que concurría cada semana al salón de Raquel para peinarse con el brushing dominicano. Sin embargo, ella se restaba activamente de participar de la vida social del lugar. Mientras estaba en el salón, se mantenía en silencio mirando su celular, sin interactuar con quienes estaban allí. Melisa explicaba que no se sentía parte de ese grupo de mujeres ya que, en una adscripción de clase, señaló que ella pertenecía a un estrato socioeconómico más alto: "voy al salón solo para peinarme y me voy. No me gusta todo ese relajo que se hace ahí". De tal modo, manifestaba su desagrado por el ambiente de "relajo" que se formaba los sábados en ese espacio, pero al mismo tiempo no podía dejar de ir cada semana, en la medida que consideraba que "solo la mujer dominicana sabe peinar nuestro cabello". Así, Melisa marcaba cierta diferencia de clase con las mujeres de la peluquería, al tiempo que compartía con ellas un sustrato común de orden etnoracial que se materializaba en lo que denominaba como "nuestro cabello".

\section{Peluquerías internacional-dominicanas en Santiago como espacios de disputa, resistencias y transacciones}

Como se ha dicho, la instalación de las peluquerías dominicanas en Estación Central se consideran una estrategia identitaria de este colectivo que intenta proveerse de un lugar propio desde donde disputar con otras normas y valoraciones respecto a las maneras de hacer con el alisado del cabello y el "arreglo" del cuerpo de la mujer. Estas disputas se dan en un orden de diferencias jerarquizadas con mujeres en función de asignación de ciertos atributos nacionalizados, en una jerarquía de posicionamientos desiguales en la escala global (Piscitelli, 2008).

En cuanto a las disputas que se dan respecto al arreglo del cabello de las mujeres presentes en el contexto de Estación Central, desde la peluquería internacionaldominicana, a las mujeres colombianas se las considera como semejantes en su preocupación por el arreglo del cabello y su apariencia corporal. En función de la identificación con este aspecto se generaban alianzas (se las considera como posibles clientas), pero también disputas y competencias. Mientras que respecto al arreglo de las mujeres peruanas y chilenas se consideraba que tenían un arreglo deficiente, como cuando Raquel decía (dirigiéndose a la investigadora): "Ustedes se arreglan poco. Ustedes no se peinan, salen con el pelo todo desordenado y se quedan, como dicen ustedes, chasconas". Y, como se ha dicho, se ubicaba a las mujeres haitianas en el lugar 
más bajo de la escala de valoraciones respecto a su preocupación por el arreglo del cabello, por tanto, respecto a ellas se trataba de una franca oposición y desprecio.

Por una parte, en relación con las mujeres colombianas afrodescendientes se las valoraba por su preocupación por el alisado el cabello lo que las constituía como potenciales clientas. Lo anterior, era confirmado por mujeres colombianas que iban habitualmente a la peluquería dominicana para hacerse el alisado y brushing dominicano. Ramona, mujer colombiana que vivía hace cuatro años en Chile y trabajaba en el servicio doméstico, era clienta de la peluquería de Juan y contaba que: "fui a una peluquería chilena donde me lo quemaron [el cabello] y después una amiga me recomendó venir aquí porque saben cómo hacerlo bien". De manera que, en tanto el cabello rizado se considera un rasgo corporal de su afrodescendencia que le es común con las mujeres dominicanas, ella valora el conocimiento de las peluqueras de esa nacionalidad sobre como alisarlo sin dañarlo.

Sin embargo, como se ha dicho, con las mujeres colombianas también se daban disputas. Es así como en una ocasión entró a la peluquería de Raquel una mujer colombiana que buscaba hacerse un decorado de uñas con diseños "colombianos". Lorena, mujer dominicana que hacía la manicure en la peluquería de Raquel los sábados, parecía no entender qué quería decir la mujer con "diseños colombianos", de manera que la potencial clienta buscó en su celular unos ejemplos y se los mostró diciendo: "mira qué lindo, así lo hacen allá, con muchos dibujos". Lorena respondió que ella no sabía hacer eso. Daba la impresión de estar molesta por las indicaciones de la mujer y, aun cuando finalmente le hizo el trabajo, cuando este estuvo terminado la clienta colombiana comentó que el decorado estaba muy simple y el precio era caro, "Ustedes no lo hacen como en mi país". Lo que marca una diferencia nacionalizada, donde se da una disputa respecto a la manera de hacer el decorado de uñas.

En relación con las mujeres peruanas del sector que llegaban a la peluquería ocasionalmente, Raquel marcaba diferencias en el modo en que aprecian el alisado y el peinado. Ella evaluaba que no destinaban mucho tiempo e importancia al arreglo del cabello: "no dejan que uno se demore 'pasando el blower', les molesta (...) no les gusta que uno les haga la vuelta hacia adentro al final de cada mechón, lo prefieren así recto", lo que a Raquel le parecía demasiado simple y sin gracia.

De manera que en tanto la valoración positiva del cabello liso no era exclusiva de las mujeres dominicanas, sino que también de las mujeres colombianas, chilenas y peruanas, ellas llegaban en ocasiones a peinarse y alisarse a la peluquería de Raquel. Sin embargo, la mayoría no permanecía como clientela habitual por las diferencias y disputas que se daban respecto a las maneras de hacerlo, es decir, a los procedimientos con los cuales se logra.

Respecto a los procedimientos de las mujeres chilenas para realizar el alisado, Raquel explicaba:

Aquí usan mucho la plancha y eso no es bueno porque quema el cabello (...) a las chilenas no les gusta que les sequemos mucho con el blower porque dicen que les maltrata el pelo (...) prefieren la plancha, pero ¡eso es lo que más lo quema! Aunque es mucho más fácil y rápido, pero me sentía que ¡no les estaba haciendo ná!

De tal modo, en cuanto a las diferencias y disputas que se daban con las mujeres colombianas, peruanas y chilenas hay que decir, por una parte, que las peluquerías 
internacional-dominicanas de Estación Central se configuran como un espacio "culturalmente construido y jerárquicamente ordenado, por un conjunto de relaciones que producen diferencias" (Sorensen, 2005, p. 167). Es decir, en el cual no solo encontramos prácticas que producen identificación y pertenencia en clave nacional, sino que con ello se dan procesos de diferenciación con las otras prácticas de arreglo del cuerpo de la mujer del contexto local.

Ahora bien, como hemos señalado, dichas diferenciaciones no operan de manera homogénea, sino que se distribuyen diferencialmente según como se las ubica discursivamente en la jerarquía de valoración, compartida por las mujeres de las peluquerías.

Si bien, en los estudios sobre peluquerías en contexto migratorio se las ha considerado como espacios transnacionales, ya que allí se reproducen normas del contexto social y cultural dominicano "(...) independientemente de si las mujeres se encuentran en República Dominicana o en Nueva York" (Amezquita, 2010, p. 15). Sin embargo, en la relocalización de las peluquerías dominicanas en Estación Central se nota que, si bien aquellos marcos de referencia y valoraciones culturales que viajan con las mujeres dominicanas se ponen en práctica en las peluquerías, estas entran en disputa con el contexto local. De tal manera, no se trata de la reproducción de lo mismo independientemente de donde se encuentran localizadas, sino que se dan transacciones entre maneras de hacer, en este caso con el alisado del cabello, de modo tal que se van incorporando en la práctica procedimientos del contexto local aun cuando no sean valorados por ellas. Tal es el caso del procedimiento de uso de la "plancha", aquel artefacto eléctrico que se utiliza para alisar el cabello y que Raquel considera dañino y demasiado simple su resultado. Sin embargo, con el propósito de atraer clientela chilena y peruana ha ido incorporando la plancha en sus prácticas cotidianas de alisado del cabello en su peluquería, lo usa "situacionalmente" (Piscitelli, 2008) para alcanzar ciertos propósitos.

Ahora bien, estos procesos de contacto con la diferencia en las prácticas, sus marcos valorativos y normativos, son bidireccionales ya que, por una parte, se consideraba que las mujeres dominicanas en Santiago han ido perdiendo la práctica del alisado del cabello: "Aquí las dominicanas se relajan con eso". A la vez, se comparte la apreciación de que las mujeres chilenas "ahora se arreglan más, se han ido contagiando" de la práctica de arreglo de las mujeres dominicanas y colombianas. Lo anterior da cuenta de una afectación mutua en el contacto, de contagio con las diferencias culturales (Bhabha, 2011). En otras palabras, el espacio de las peluquerías se puede concebir como una zona de afectaciones entre prácticas diversas y los marcos normativos y valorativos que las sostienen.

Otro ámbito de transacciones es en el uso situacional de las maneras de decir, la utilización de modismos para el logro de fines. Un ejemplo de aquello era cuando, al hablar con una clienta chilena, Raquel usaba la palabra "chascón", ${ }^{7}$ con el fin de generar confianza en la clienta. Estas tácticas constituyen transacciones con lo local, maneras de "valerse de los modos de hablar del lugar como astucia y táctica" (De Certeau, 1996b, p. 46), lo que les permiten moverse en distintos espacios sociales en su vida cotidiana en Santiago.

\footnotetext{
${ }^{7}$ Modo de nombrar en Chile un cabello despeinado.
} 
Ahora bien, en el ámbito de la incorporación de modismos también se daban resistencias, es decir, como señala Salazar Parreñas (2001), intentos de mitigación o incluso de eliminación de su dislocación. Lo anterior se ponía en juego al tener una conversación con personas chilenas, en donde les resultaba necesario explicitar la referencia de la palabra antes de usarla, indicando: "como dicen ustedes", clarificando que se usa para darse a entender, pero no le pertenece. Mientras que cuando se hablaba entre mujeres dominicanas, no parecía necesario mencionar su referencia nacional, pero su uso espontáneo se interpretaba como "estarse chilenizando". Este proceso muchas veces era resistido por las mujeres, como cuando Raquel señaló que ella no utiliza la palabra "cachai" ya que le parecía que se escucha mal dicho por ellas: "a nosotras no nos queda bien hablar así como a ustedes, no se escucha bien en nosotras". Esto opera como resistencia en la medida en que se concibe que el acento nacional corresponde, para que resulte coherente, a una nacionalidad — solo una-, de manera que toda fonación híbrida y acento mezclado que no se ciña a la forma esperada, al canon nacional, resulta inquietante y, a veces, molesto.

Por último, se identificó otro modo de resistencia a la incorporación de modismos, que consistía en utilizar las palabras consideradas chilenas haciendo una mímesis (Bhabha, 2011) o actuación exagerada en el momento de decirlo. Así, se expresaba la palabra con una pronunciación y modulación acentuada con intensidad, mostrando que se las utiliza, pero no les son "propias". De tal manera, en una ocasión hacía el final del sábado, la cerveza se había terminado y uno de los hombres presentes se levanta y dice "vamos a hacer una vaca", lo cual es una forma común en Chile de decir "hacer una colecta" de dinero entre las personas presentes. Así, mientras él pasaba recibiendo el dinero decía "ipongan una luca!", haciendo una mímesis exagerada que dejaba en claro que no era chileno, pero que al usar esas palabras actuaba como tal. Estas resistencias y transacciones descritas en la utilización de ciertos modismos locales se entienden como marcas en las maneras de decir que dan cuenta de una cierta posición subjetiva respecto a su experiencia migratoria.

\section{Conclusiones}

En este artículo se propuso documentar y describir algunas de las prácticas cotidianas que se realizan en el espacio de las peluquerías internacional-dominicana en Estación Central y la función que estas cumplen en la vida cotidiana de las mujeres dominicanas que allí concurren. Respecto a aquello, se concluye que dichos espacios constituyen, por una parte, una estrategia identitaria que intenta hacerse de un lugar propio para el grupo de mujeres y hombres dominicanos que habitan o trabajan en el sector de Estación Central. Así, la peluquería se concibe "como la embajada de nosotros", es decir, "el lugar donde te sientes como en tu casa", lo que les provee de un espacio de relajo de las presiones en su vida cotidiana en Santiago como mujeres inmigrantes de baja calificación. Lo anterior se expresa en que allí las mujeres "se peinan unas con otras" como si estuvieran en el patio de las casas, pueden "hablar, así como en charcha" y tomar café mientras se van contando sus problemas con el trabajo, con los documentos de migración o con los maridos. Lo anterior hace que las peluquerías

\footnotetext{
${ }^{8}$ Modo de decir en Chile “¿entiendes?” y se usa regularmente al final de una frase.
} 
se experimenten como espacio público, en tanto negocio de servicios de belleza, y por momentos también como espacio íntimo y de relajo entre mujeres. Asimismo, la peluquería, como intento de darse un lugar propio para el grupo de mujeres dominicanas que son su clientela estable, se organiza en torno a la práctica del alisado del cabello afro y el brushing dominicano, el cual es considerado por ellas como "lo más propio de la mujer dominicana".

Sin embargo, las prácticas cotidianas de las peluquerías "internacional-dominicanas" no se reproducen idénticas a sí mismas o a su original "dominicano", sin importar donde se ubiquen. Por el contrario, desde el espacio de las peluquerías como intento de lugar propio se dan disputas, resistencias y transacciones con lo local que van modificando en parte sus prácticas.

Aquellas resistencias, transacciones y disputas refieren tanto a las maneras de decir, como a las maneras de hacer con el peinado y alisado del cabello afro, a lo que se entiende como el "arreglo" del cuerpo de la mujer. Así las peluquerías, al estar relocalizadas en Santiago, se configuran como un espacio de contacto con la diferencia: de alianza y disputas con las mujeres colombianas, de diferenciación y superioridad con las mujeres chilenas y peruanas, y de abierto rechazo respecto a las mujeres haitianas. A la vez que, cuando la estrategia identitaria falla y la peluquería no logra sostenerse económicamente con los servicios del alisado de los cabellos afro, se utilizan tácticas con las cuales se van incorporando situacionalmente del contexto local procedimientos para alisar el cabello y modismos que les permiten atraer clientela de otras nacionalidades.

Estas tácticas van formando un "tejido contaminado pero conectivo (...) un acto complejo que genera afectos e identificaciones fronterizas, 'tipos singulares de simpatía y choque entre culturas' (...) el 'entre-medio' [In-between] de la cultura, desconcertantemente parecido y diferente" (Bhabha, 2011, p. 96). Lo anterior se expresa en la evaluación que se hace tanto de las mujeres dominicanas en Chile que "se relajan" con el alisado del cabello afro, como de las mujeres chilenas que se han ido "contagiando" con las prácticas de arreglo de las mujeres dominicanas y colombianas. De tal modo, estos procesos se alejan de una lógica lineal y unidireccional en los procesos de aculturación como es la idea de asimilación, que opera con el supuesto de la absorción pasiva de la cultura del otro por el migrante. Se trata más bien de procesos de afectación mutua que configura a las peluquerías como un espacio que no es por completo dominicano ni totalmente internacional, sino que se trata de una zona intermedia, en un intervalo que se indica con aquel guion: "internacionaldominicana”, es decir, que se ubica a la vez dentro y fuera del territorio nacional, sus prácticas y valoraciones.

Es así como en la diseminación de dominicanos y dominicanas en el mundo, en aquellas ciudades donde se concentran, las peluquerías funcionan como espacios de contacto con la diferencia e identificación como "dominicanos en el exterior". Es decir que, sin dejar el anclaje nacional, se reconocen como estando fuera, y dicha exterioridad se expresa tanto en las maneras de hacer como de decir. Una limitación de esta indagación, sin embargo, es no haber podido explorar estas prácticas desde la dimensión de género incorporando la perspectiva masculina, presente también en las peluquerías dominicanas en Santiago. 


\section{Referencias}

Alcalde, R. (2011). Cosas de mujeres: familias monoparentales dominicanas en Barcelona y en Nueva York. Revista Internacional de Organizaciones, 6, 109-134. https:/ / doi.org/10.17345/rio6.109-134

Amezquita, G. (2010). Hair raising power: Dominican hair salon owners in New York City (African \& African American Studies Senior These, Fordham University). https://fordham.bepress.com/cgi/viewcontent.cgi?referer=https://www.google.com /\&httpsredir=1\&article=1037\&context=aaas_senior

Arango, L. G. (2011). Género, belleza y pretensiones artísticas en el campo de las peluquerías. Revista Latina de Sociología, (1), 1-44. https://ruc.udc.es/dspace/bitstream/handle/2183/11998/RLS_1_2011_art_1.pdf?sequence=1\&isAllowed=y

Ariza, M. (2012). Vida familiar transnacional en inmigrantes de México y República Dominicana en dos contextos de recepción. Si Somos Americanos. Revista de Estudios Transfronterizos, 12(1), 17-47. https://scielo.conicyt.cl/pdf/ssa/v12n1/ art02.pdf

Atisba Monitor. (2018). El mapa de la inmigración en Santiago. Localizaciones espacial inmigrantes. Censo 2017. http://www.atisba.cl/wp-content/uploads/2018/07/Reporte-Atisba-Monitor_Mapa-Inmigraci\%C3\%B3n-en-Santiago.pdf

Barral Mallimaci, A. I. (2011). Migraciones y géneros. Formas de narrar los movimientos por parte de migrantes bolivianos/as en Argentina. Estudos Feministas, 19(3), 751-775.

Bartkowski, F. (1995). Travelers, Immigrants, Inmates. Essays in Estrangement. University of Minnesota Press.

Bhabha, H. (2010). DisemiNación. Tiempo, narrativa y los márgenes de la nación moderna. En H. K. Bhabha (Dir.), Nación y narración entre la ilusión de una identidad y las diferencias culturales (pp. 385-421). Siglo XXI.

Bhabha, H. (2011). El lugar de la cultura. Manantial.

Bissainthe,J. G. (2003). Migración transnacional: dominicanos en New York City. Ciencia y Sociedad, 28(1), 128-160. http://www.redalyc.org/articulo.oa?id=87012383006

Bleichman, S. (2010). El desmantelamiento de la subjetividad. Estallido del yo. Topía.

Bravo, G. (2015). Las migraciones internacionales y la seguridad multidimensional en tiempos de globalización. Diálogo Andino, 48, 139-149. https://doi.org/10.4067/ s0719-26812015000300013

Butler, J. (2005). Cuerpos que importan. Sobre los límites materiales y discursivos del "sexo". Paidós.

Butler, J. (2017). Cuerpos aliados y lucha política. Hacia una teoría performativa de la asamblea. Paidós.

Candelario, G. (2000). Hair Race-ing: Dominican Beauty Culture and Identity Production. Meridians, 1(1), 128-156.

Candelario, G. (2007). Introduction. "We Declare That We Are Indians": Dominican Identity Displays and Discourses in Travel Writing, Museums, Beauty Shops, and Bodies. En G. Candelario, Black Behind the Ears: Dominican Racial Identity from Museums to Beauty Shops (pp. 1-33). Duke University Press. 
Cea-Merino, P., Galaz, C. \& Montenegro-Martínez, M. (2015). La construcción social de las mujeres inmigrantes en los discursos de la academia. Psicoperspectivas. Individuo y Sociedad, 14(2), 28-39.

De Certeau, M. (1996a). Relatos de espacio. "Espacios" y "lugares”. En L. Giard (Ed.), La invención de lo cotidiano. 1. Artes de hacer (pp. 127-142). Universidad Iberoamericana, Instituto Tecnológico y de Estudios Superiores de Occidente.

De Certeau, M. (1996b). Valerse de: usos y prácticas. En L. Giard (Ed.), La invención de lo cotidiano. 1. Artes de hacer (pp. 35-48). Universidad Iberoamericana, Instituto Tecnológico y de Estudios Superiores de Occidente.

De la Torre, R. (2018). Itinerarios teórico-metodológicos de una etnografía transnacional. Revista Cultura y Representaciones Sociales, 12(24), 17-50.

Foucault, M. (2001). La hermenéutica del sujeto. Curso en el Collège de France (19811982). FCE.

Galaz, C., Rubilar, G. \& Silva, C. (2016). Boletín informativo. Departamento de Extranjería y Migración. Migración Dominicana en Chile, (2). https://www.extranjeria.gob.cl/ media/2016/12/Bolet\%C3\%ADn-N\%C2\%BA2-Migraci\%C3\%B3n-Dominicana-en-Chile-2.pdf

Garcés, A. (2011). Comercio inmigrante y economías étnicas: síntesis y críticas de los debates vigentes. Polis (Santiago), 10(29), 97-122. https://doi.org/10.4067/ s0718-65682011000200005

Godreau, I. (2002). Peinando diferencias, bregas de pertenencia: el alisado y el llamado 'pelo malo'. Caribbean Studies, 30(1), 82-134.

Gregorio, C. (1998). Migración femenina: su impacto en las relaciones de género. Narcea.

Guizardi, M., Gonzálvez, H. \& Stefoni, C. (2018). De feminismos y movilidades. Debates críticos sobre migraciones y género en América latina (1980-2018). Rumbos, 13(18), 37-66.

Hall, S. (2003). ¿Quién necesita 'identidad'? En S. Hall \& P. Du Gay (Eds.), Cuestiones de identidad cultural (pp. 13-39). Amorrortu.

Instituto Nacional de Estadísticas de Chile (INE). (2018). Características de la inmigración internacional en Chile. Censo 2017. http://www.censo2017.cl/descargas/inmigracion/181123-documento-migracion.pdf

Laclau, E. (1993). Nuevas reflexiones sobre la revolución de nuestro tiempo. Nueva Visión.

Lara, A. (2019). Acento: voz y nación en los desplazamientos migratorios. Revista Simbiótica, 6(1), 232-254. http://periodicos.ufes.br/simbiotica/article/ view/27205/18355

Lara, A. (2020). «El alisado es lo más propio de la mujer dominicana»: prácticas ritualizada y mimética del «brushing dominicano». Polis, 55. https://dx.doi. org/10.32735/S0718-6568/2020-N55-1443

Magliano, M. J. (2015). Interseccionalidad y migraciones: potencialidades y desafíos. Revista Estudos Feministas, 23(3), 691-712. https:/ / doi.org/10.1590/0104-026X2 015v23n3p691

Mansilla, P. \& Imilán, W. (2018). Reterritorializaciones migrantes a través del cuerpo y su expresividad. Estudios Atacameños, (60), 241-256. https://revistas.ucn.cl/index.php/estudios-atacamenos/article/view/777

Mayol, P. (1999). Capítulo I: El Barrio. En M. De Certeau, L. Giard \& P. Mayol, La invención de lo cotidiano 2. Habitar, cocinar (pp. 5-12). Universidad Iberoamericana. 
McClintock, A. (1995). Imperial Leather: Race, Gender and Sexuality in the Colonial Contest. Routledge.

Mora, C. (2008). Globalización, género y migraciones. Polis, 7(20), 285-297. https:// doi.org/10.4067/s0718-65682008000100015

Organización Internacional para las Migraciones (оIM). (2017). Perfil migratorio de República Dominicana. Organización Internacional para las Migraciones, Instituto Nacional de Migración de República Dominicana.

Oso, L. \& Parella, S. (2012). Presentación. Cuadernos de Relaciones Laborales, 30(1), 11-44.

Piscitelli, A. (2008). Interseccionalidades, categorias de articulação e experiências de migrantes brasileiras. Sociedade e Cultura, 11(2), 263-274. https://doi. org/10.5216/sec.v11i2.5247

Quiñones, M. I. (2007). Beauty Salons: Consumption and the Production of the Self. En F. Negrón-Muntaner (Ed.), None of the Above: Puerto Ricans in the Global Era (pp. 109-128). Palgrave Macmillan.

Rangelova, R. (2013). La ciudad de la mujer: solidaridad y resistencia en el salón de belleza. Letras Femeninas, 39(1), 107-122.

Reguillo, R. (2000). La clandestina centralidad de la vida cotidiana. En A. Lindon (Coord.), La vida cotidiana y su espacio-temporalidad (pp. 77-94). El Colegio Mexiquense, A. C., Anthropos.

Reyes-Santos, I. (2008). Capital neoliberal, raza, migración: análisis comparativo de relaciones domínico-haitianas y domínico-puertorriqueñas. Revue Européenne des Migrations Internationals, 24(1), 13-34. https://doi.org/10.4000/remi.4245

Salazar Parreñas, R. (2001). Servants of Globalization. Women, Migration and Domestic Work. Stanford University Press.

Segato, L. R. (2007). La Nación y sus otros: raza, etnicidad y diversidad religiosa en tiempos de políticas de la identidad. Prometeo.

Sorensen, N. (2005). Migración, género y desarrollo: el caso dominicano. En N. Zúñiga (Coord.), La migración: un camino entre el desarrollo y la cooperación (pp. 163182). Centro de Investigación para la Paz/cIP/Fundación Hogar del Empleado.

Sorensen, N. (2006). Narrating identity across Dominican words. En M. P. Smith \& L. E. Guarnizo (Eds.), Transnationalism from Below (pp. 241-270). Transaction Publishers.

Tejeda, E. (2016). La emigración dominicana: cifras y tendencias. 2015. A. J. Petrozziello (Ed.), Estado de las migraciones que atañen a la República Dominicana 2015 (pp. 67-80). Obmica/Editora Búho.

Torres-Saillant, S. (2012). El anti-haitianismo como ideología occidental. Cuadernos Inter.c.a.mbio, 9(10), 15-48.

Tubert, S. (2010). Los ideales culturales de la feminidad y sus efectos sobre el cuerpo de las mujeres. Quaderns de Psicología, 12(2), 161-174.

Velasco, H. \& Díaz de Rada, A. (1997). La lógica de la investigación etnográfica. Un modelo de trabajo para etnógrafos de escuela. Trotta. 
Antonia Lara

Chilena. Doctora en ciencias sociales por la Universidad de Chile. Docente investigadora del Centro de investigación en Ciencias Sociales y Juventud de la Universidad Católica Silva Henríquez. Líneas de investigación: migraciones, género y racialización, procesos de subjetivación, malestar subjetivo y migración. Publicaciones recientes: Lara, A. (2019). Acento: voz y nación en los desplazamientos Migratorios. Simbiótica, 6(1). Lara, A. (2019). Perspectiva de atención psicoterapéutica a personas en situación de refugio". REMHU, 27(55), 97-112. 